objects. The Branch also permits each year one firm of suppliers of apparatus to provide an exhibit. The layout of the exhibits was admirable, the Great Hall of the College giving ample space for complete inspection.

\section{Symposium in Geneva on High-Energy Physics}

The European Organization for Nuclear Research is holding an international symposium on "HighEnergy Physies" during June 11-23 in the Institute of Physics of the University of Geneva. Some three hundred scientific workers from twenty countries will attend the symposium; they will include approximately one hundred and sixty from the twelve member States of the Organization, about sixty each from the United States and the U.S.S.R., and a number from Australia, Canada, Czechoslovakia, India, Japan and Spain. In addition, about a hundred members of the scientific staff of the Organization will be participating. During the first week the main discussions at the symposium will be on novel features in the design and techniques of high-energy particle accelerators; the first few days of the second week will be devoted to newly developed techniques for the detection and measurement of fast particles, such as bubble chambers and over-compression cloud chambers, and during the latter part of the week $\pi$-mesons and the anti-proton will be considered.

\section{Announcements}

THE Geological Society of London has awarded the R. H. Worth Prize for 1955 to Mr. James Wright, and the Prize for 1956 to Dr. C. T. Trechmann; these Prizes are from a fund established under the will of the late Richard Hansford Worth, of Ply. mouth, "to provide a prize or prizes for the encouragement of amateur geological research". The Daniel Pidgeon Fund for 1956 of the Society has been awarded to Dr. K. A. Joysey, of the Department of Zoology, University of Cambridge, who is studying the variation in living and fossil echinoid species in order to assess the stratigraphic and systematic significance of this variation.

THE following, among others, have been appointed to chairs in the newly established Medical School of the University of Western Australia, Perth: Anatomy, Dr. D. C. Sinclair, University demonstrator in human anatomy, Oxford; Medicine, Dr. E. G. Saint, director of the Clinical Research Unit in the Royal Perth Hospital, Western Australia, and formerly of the Department of Industrial Health, King's College, Newcastle upon Tyne; Microbiology, Dr. N. F. Stanley, director of the Institute of Epidemiology and Preventive Medicine, Prince Henry Hospital, Adelaide.

THE College of Technology, Bristol, in collaboration with the Regional Council for Further Education for the South West, has arranged a course during July 6-7 on "The Applications of Radioactive Isotopes in Industry and their Uses as Tracers". The course is designed for chemists, engineers and technologists from industry. The fee, exclusive of accommodation, is one guinea. Further information can be obtained from the Department of Chemistry and Biology, College of Technology, Bristol 1.

A summer course on "Oilfield Reservoir Engineering" will be held in the University of Birmingham during July 2-28. The course, which will be residential, will comprise lectures by members of the
Petroleum Production Department of the University and specialist lecturers from industry, including, in particular, the British Petroleum Co., Ltd. Further information can be obtained from H. Gilmour, Petroleum Production Department, University, Edgbaston, Birmingham 15.

THE Association of Applied Biologists will hold its summer meeting in Northern Ireland during July 19-21. After the reading of a number of papers on July 20 at The Queen's University of Belfast, the succeeding days will be devoted to tours of the Counties of Antrim, Londonderry, Down and Armagh. Further information can be obtained from the honorary local secretary, Dr. J. Colhoun, Depart. ment of Mycology and Plant Pathology, The Queen's University, Belfast.

A TWO-DAY summer meeting of the Royal Meteorological Society will be held in the University College of Wales, Aberystwyth, during July 26-28. On the first day there will be papers on ionization methods of measuring air density and a discussion on airflow, and on the next day papers on aspects of local climatology will be followed by a discussion on orographic effects in relation to rainfall. Further information can be obtained from the Assistant Secretary of the Society at 49 Cromwell Road, London, S.W.7.

A Conference on "Magnetism and Magnetic Materials", organized by the American Institute of Electrical Engineers in co-operation with the American Physical Society, the American Institute of Mining and Metallurgical Engineers, and the Institute of Radio Engineers, will be held in Boston during October 16-18. Those who wish to read papers should send in the titles by June 15, and abstracts by August 1, to T. O. Paine, Measurements Laboratory, General Electric Company, West Lynn, Mass., from whom further information can be obtained.

A symposium on "X-Ray Microscopy and Microradiography", sponsored by the International Union of Pure and Applied Physics, will be held in the Cavendish Laboratory, Cambridge, during August 16-21. The symposium is intended to be a gathering of those with some direct experience or interest, rather than a large public conference, and primary emphasis will be placed on the physical methods, in theory and practice. Sessions are planned on the reflexion, contact and projection methods, respectively; sessions will also be devoted to applications in biology, medicine, metallurgy and other fields, including industrial applications. Further information can be obtained from Dr. W. C. Nixon, Cavendish Laboratory, Cambridge.

THE eleventh annual conference and exhibition of the Instrument Society of America will be held in New York during September 17-21. The exhibition, which will be in the Exhibition Hall of the New York Coliseum, is for manufacturers and their representatives to display their range of instruments and control apparatus used in scientific, technological and engineering work; in particular, emphasis will be placed this year on the application of instruments to automation in industry. Further information can be obtained from the exhibition manager, Fred J. Tabery, Eleventh Annual Instrument-Automation Conference and Exhibit, 250 West 57th Street, Ne York City. 